\title{
Drug discovery in jeopardy
}

Pedro Cuatrecasas

Departments of Pharmacology and Medicine, University of California San Diego, San Diego, California, USA.

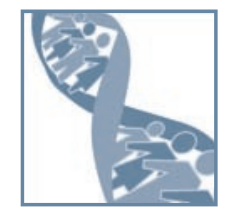

Despite striking advances in the biomedical sciences, the flow of new drugs has slowed to a trickle, impairing therapeutic advances as well as the commercial success of drug companies. Reduced productivity in the drug industry is caused mainly by corporate policies that discourage innovation. This is compounded by various consequences of mega-mergers, the obsession for blockbuster drugs, the shift of control of research from scientists to marketers, the need for fast sales growth, and the discontinuation of development compounds for nontechnical reasons. Lessons from the past indicate that these problems can be overcome, and herein, new and improved directions for drug discovery are suggested.

The decreasing output of new drugs and the drying up of industry pipelines are well established (1-4). To maintain profitability, the pharmaceutical industry has resorted to practices that have drawn public criticism, including markedly increasing drug prices, increasing spending on advertising and promotion, direct-to-consumer advertising, ineffectively conducting postmarketing surveillance, and limiting comparative efficacy/safety studies with alternative drugs. However, attention should be directed more to the root of these problems - the inefficiencies of drug discovery and development (D\&D), which result from the management policies and corporate cultures of the institutions (corporations) that undertake the research and development $(\mathrm{R} \& \mathrm{D})$. These conditions are so entrenched that we must ponder whether the current system can recover.

\section{What is really wrong?}

Low productivity. The low productivity (1-4) of drug D\&D is certainly not related to available budgets, which have increased 30-fold since 1970. Many Pharmas devote more than $\$ 5$ billion/ year to $R \& D$, with over $\$ 30$ billion/year of cumulative spending, greater that the total NIH budget of $\$ 28$ billion. The falling productivity has been ascribed commonly to a number of well-discussed factors such as regulatory hurdles and high attrition of drug candidates (1-4). Most of these issues are contributory rather than fundamental; at the heart of the problem are the more profound underlying dynamics that drive R\&D.

The FDA oversees drug development and approval of new drug applications (NDAs). While the regulatory requirements are well warranted, grossly inadequate resources (5) have resulted in an antiquated process of NDA review that is slow, sometimes of poor quality, and at times subject to political influence. Other issues include the retraction of agreed-upon requirements for approval, the current crisis of FDA leadership (e.g., absence of a permanent commissioner), and the inappropriate role of ideology in decisionmaking (e.g., the case of approval for the "morning-after" pill). Other critiques can be found elsewhere (e.g., in refs. 1-4 and 5-8). Although significant reforms are in order, the FDA or regulatory issues are not fundamental barriers and contribute only marginally to the decline in drug productivity.

Nonstandard abbreviations used: $C E O$, chief executive officer; $D \& D$, discovery and development; NDA, new drug application; R\&D, research and development.

Conflict of interest: The author is a consultant to Daiichi Sankyo Research Institute and a member of the board of directors of Alliance Pharmaceutical Corp.

Citation for this article: J. Clin. Invest. 116:2837-2842 (2006). doi:10.1172/JCI29999.
Likewise, we cannot blame the current state of scientific advances, which in the last 20 years have been revolutionary. These advances offer mind-staggering new opportunities in innovative drug discovery and development. It is also fallacious to suggest that the decrease in new drugs is due to our already having conquered the "easy" diseases, a rationalization repeatedly expressed for 3 decades.

The complex, lengthy, and unpredictable nature of drug R\&D certainly contributes significantly to high costs and inefficiencies. For example, only 1 or 2 of every 10 compounds entering the phase of human clinical trial ever reaches the market. However, this high rate of loss of drug candidates during development (i.e., attrition) is not greater today than in past decades. As will be elaborated, the current problem of low productivity relates instead primarily to the pervasive mismanagement of the already difficult $R \& D$ process.

Changes in the approach to management. Foremost among the issues that cripple drug $R \& D$ is that while utmost creativity and innovation are required, the $\mathrm{R} \& \mathrm{D}$ is conducted in traditional for-profit corporations that are virtually indistinguishable operationally from those that conduct little or no R\&D. Most corporations' top management does not understand the complexities of science, its mode of conduct or objectives, and runs the companies in ways that stifle creativity and innovation (9, 10). Prior to 1980 , most drug companies functioned differently. They were smaller than today's companies, and the nontechnical executives knew and were proud of their scientists and were more likely to allow R\&D staff to pursue objectives with little interference. Informal systems dominated behavior. Each company had its unique ways, history, character, and culture. Most appreciated that their existence and fortunes were based on a combination of need and economic benefit, such that profitability was balanced with public responsibility. This tended to minimize the overpricing of drugs. A corporate identity of (and pride in) uniqueness of purpose were evident. Employees felt they were contributing to the improvement of human health.

In the 1970s things began to change. Modern managers entered as chief executive officers (CEOs) and other high-level executives, mostly with little or no technical experience. Many had legal or business school training or came from non-drug industries that functioned with greater organizational discipline. Those promoted internally were often from legal or finance departments, with little or no experience in research, manufacturing, or engineering. Most were unacquainted with research and were uncomfortable with seemingly "unfocused" research organizations that they per- 
ceived to operate in a freewheeling, independent style. These executives found comfort in outside management consulting firms that were called upon to suggest structural reshapings and behavioral changes. Corporate management had an instrument by which to introduce order into the research establishments (10).

Unfortunately, while consulting firms had experience in advising non-technology-based corporations, few were familiar with drug companies or complex professional-based matrix organizations. Their recommendations to change organizational structures, procedures, and even program and project portfolios were patterned after companies with which they were familiar, such as General Electric and other so-called well-managed companies.

\section{Shareholders, investment bankers, and analysts, who know little about drug discovery, place intense pressures on CEOS and their boards for quick returns.}

Use of these consulting firms became so fashionable that virtually every Pharma underwent similar externally driven reshaping in an effort to manage and control its scientific enterprise. Further, by popularizing "benchmarking," a process in which companies review their activities against what others are doing, rather than exploiting their own unique skills and experience, drug companies began to all look alike (10).

Conformism. With such restructuring, drug companies now felt more confident that they could manage and mandate results with discipline, order, formality, and efficiency. Unfortunately, many of these qualities are ones that suffocate creativity and innovation. Freedom, spontaneity, flexibility, nimbleness, tolerance, compassion, humor, and diversity were replaced by bulky and inflexible organizational structures characterized by regimentation, control, conformity, and excessive bureaucracy. Managers often overfocused and employed top-down decision-making (10). The objective outcomes resulted in more mediocre, not novel, products, and there was no evidence of improved long-term profitability. Ironically, great-sounding slogans were used to achieve conformity while proclaiming the importance of innovation, empowerment, diversity, and compassion.

Managers, not leaders. It is understandable that most corporate human resources departments are unaware of some of these issues. However, top research managers can unfortunately be similarly uninformed. Most rise through the ranks by satisfying superiors and are selected by nontechnical management (and human resources programs) as "good company players." While outstanding scientists are often recruited for high leadership roles in research, the "learn about industry" education process and lure of power can ultimately result in an intellectual shortsightedness regarding science. For some, the financial incentives are important. Of course, many of the best-qualified who cannot adjust depart quietly, while others find ways to quixotically manage the system and foster creative environments and research programs. There are still companies that try to focus on excellent science and that attract first-rate scientists. These are, however, exceptional situations.

Drug R\&D thrives in a creative, flexible, and nonautocratic environment (9). Success depends on individual freedom and inspiration rather than dogmatic leadership. Instead, in "well-run" corporations today, scientists must contend with "management by objectives," hierarchical and autocratic organizations, mandates from strategic planning groups, detailed and rigid scheduling, constant reporting, and achievement driven by milestones and flowcharts. Normally, rewards are based on quantitative output (number and weight of reports or numbers of compounds or tests) and extrinsic incentives such as money, promotion, power, and visibility. Is it any wonder that true innovation cannot thrive?

Pressures from shareholders. The ownership of public companies consists mainly of shareholders who expect rapid (and substantive) returns on their investments. This contrasts (and often conflicts) with the nature of the business objectives, which must be based on long-term investments in science and technology. This dilemma is illustrated by the requirements for quarterly reporting of earnings versus the 10- to 20-year cycles of business operations (product projects). Companies have managed to navigate through this quandary, but it is becoming increasingly difficult.

Shareholders, investment bankers, and analysts, who know little about drug discovery, place intense pressures on CEOs and their boards for quick returns. Boards of directors, although often understanding of the CEOs' dilemma, are nevertheless forced (by their primary role of representing the interests of shareholders) to push CEOs by setting stringent, short-term financial performance outcomes for determining annual compensation. CEOs are thus under even more pressure to achieve quick results through cost-cutting, low-risk projects, and acquisitions. All too rarely, an enlightened CEO undertakes energetic efforts to educate boards and analysts regarding the nature of their business and to insist that responsibility and accountability to the public are paramount concerns that demand a long-term view and, perhaps, profit expectations more in line with those of other industries.

Merger mania. The decreasing earnings of Pharmas have stimulated mergers and acquisitions, driven by the desire to acquire existing sales (products) while decreasing costs via layoffs. This has created conditions that catalyze further inefficiencies and suffocation of innovation. The merged megacompanies' research organizations must be integrated rapidly and redundancies eliminated, oftentimes in haste. Decisions regarding people and programs are made arbitrarily, by people far removed from the science and labs. Good programs are eliminated in attempts to consolidate, and knowledge, training, and expertise, often cultivated over many years, are often lost. Active scientists can be transferred to administrative, nonscientific tasks such as project management, licensing, and planning. While these posts often appear glamorous, such appointments can remove the individual from the scientific arena and result in the loss of valuable expertise to the company.

With rapid growth and huge size come changes in bureaucratic procedures and organizational hierarchies that may be confusing or meaningless to individuals (9). Communication, so important in complex scientific undertakings dependent on teams and matrix interactions, becomes burdensome. The dispersion of personnel and projects over geographic regions or buildings is also disruptive.

Blockbuster mania. Pharmas have become much less interested in developing drugs that will sell less than $\$ 1$ billion a year. Without these "blockbusters" they cannot maintain the traditionally high profits. The loss of major drugs to patent expiration, the high-gross sales required, and the increasing costs of $R \& D$ and of advertising, promotion, and marketing require sustaining a sizable number of highly profitable new products. The larger the existing sales, the greater the need for blockbusters. 
To optimize the economic potential of new blockbuster drugs, it is necessary that, once they are marketed, the rate of sales growth be as high as possible. The "front-end" upswing benefit is due to the current value of money, maximizing patent periods, preparing for emerging competition, and the inherent promotional value of the rapid growth itself. This is so important that many corporations now even deliberately delay NDAs or marketing itself until they can amass as impressive a promotional "package" as possible. This may include studies that support other clinical indications and dosage forms, marketing support, and economic data on other "benefits," such as formularies and reimbursement.

This approach contrasts with the practices of 20-30 years ago. The rationale then was to initiate marketing more quietly with whatever was necessary to receive FDA approval and to expand the franchise gradually but solidly over ensuing years with follow-up studies and analyses based on experience. The medical community was perceived as being cautious with new medicines. The drug's labeling was revised frequently over time to reflect new indications and dosage forms, side effects, warnings, and contraindications. This approach also helped create longer-lasting brand loyalty, very important in the days before automatic generic substitution on patent expiration. The economic value of new drugs was initially lower, but it increased and was spread over many years.

A danger of today's exceedingly aggressive introduction of new drugs into the marketplace is that it is virtually impossible to obtain postmarketing data from pharmacovigilance programs. Thus, it is more likely that unexpected, serious adverse events will be discovered only after millions of drug exposures. In recent years many drugs have been withdrawn suddenly from the market, under duress, due to such unexpected and serious side effects.

Infrequent but serious adverse events can arouse significant public attention and turmoil. There is little time to scientifically evaluate possible contributing factors. The media's quest for sensationalism helps create a frenzy of emotion, misinformation, and accusations. It is nearly impossible to rationally resolve complex scientific issues under this type of public scrutiny. Thus, in many cases the only alternative is to take the drug off the market. This can be calamitous for the company as well as those patients who have suffered or who received major benefits from the drug. Many

\section{Pharmas have become much less interested in developing drugs that will sell less than $\$ 1$ billion a year.}

of the adverse events reported are clearly causally related, but attribution in other cases may be questionable. In most cases the stigma of incrimination and market withdrawal is such that no matter what the facts turn out to be, marketing cannot be restored.

Another risk of overzealous development planning for blockbuster status is that unexpected clinical or regulatory "problems" that always arise can become sufficiently discouraging to derail the drug altogether; expectations are not met, and the blockbuster status is compromised. Clearly, to better serve public safety and instill scientifically valid decision-making, and improve the long-term interests of corporations and shareholders, better systems of postmarketing surveillance are needed. But this is probably not possible without more deliberate and cautious marketing of new drugs.
The shift from Re'D to marketing. The decision that a company cannot waste resources on non-blockbuster drugs often leads to unwise decisions. Marketing departments, almost by definition, must control R\&D. They decide, ultimately, which research programs, diseases, indications, characteristics, and development compounds to pursue. Marketers rarely have interest in early-stage compounds with novel mechanisms or in unfamiliar clinical indications. They often push to discontinue (or not license-in) programs based on unsupportable commercial extrapolations, to the great frustration of scientists.

\section{Lessons from the past}

After a career in medicine and research at Washington University, the $\mathrm{NIH}$, and Johns Hopkins University, I moved my laboratory of more than 30 workers to Burroughs Wellcome Co. as head of its R\&D operations and a member of its board of directors. Subsequently, I became head of R\&D and director of Glaxo Inc. (1985-1989), then president of R\&D and corporate vice president of Warner Lambert Co. from 1989 until retirement in 1997, and continued as a consultant to the CEO and to R\&D until 2000. My broad experiences with the industrial, business, regulatory, and academic communities have helped me to formulate the opinions described here.

Some personal anecdotes. While in charge of $\mathrm{R} \& \mathrm{D}$ at Burroughs Wellcome Co. from 1975 to 1985, I witnessed many startling examples of the folly of rendering early marketing (or technical) predictions when dealing with novel compounds or diseases. During the D\&D of acyclovir (Zovirax), marketing insisted that there were "no markets" for this compound. Most had hardly heard of genital herpes, to say nothing about the common and devastating systemic herpetic infections in immunocompromised patients. But those with knowledge of clinical medicine knew that these were very serious and prevalent conditions for which there were no other therapies. Fortunately, at the time, research management had the authority and knowledge to render decisions. Zovirax entered the market, in various dosage forms and indications. At initial marketing, in 1982, of the ointment form only, the informal estimates of peak sales were about $\$ 10$ million a year for all forms of the drug, far below the annual sales of well over $\$ 1$ billion that were ultimately achieved. Marketing's main job was to distribute and sell what R\&D developed, and secondarily to provide the research staff with information and suggestions. Relations were always amicable and mutually reinforcing, despite differences of opinion. Other examples of compounds developed in that period that became blockbusters despite being considered "orphan" (rare and nonprofitable) included azidothymidine (AZT; Retrovir) for HIV, with low predicted markets initially (1981); bupropion (Wellbutrin), for markets felt to be "well satisfied" by the tricyclic antidepressants, just before the enormous success of fluoxetine (Prozac) disproved this; and colfosceril palmitate (Exosurf), for infant respiratory distress syndrome. At Parke Davis/Warner Lambert during 1989-1997, numerous other compounds would never have been marketed had it not been for the strong insistence of research management. These compounds included gabapentin (Neurontin), atorvastatin (Lipitor), troglitazone (Rezulin), fosphenytoin (Cerebyx), and pregabalin (Lyrica).

The major lesson from the stories of the development of all of these drugs, which is repeated throughout the history of drug $\mathrm{D} \& \mathrm{D}$, is that nearly all drugs that have become blockbusters (and therapeutic breakthroughs - these two normally go together) had similar early histories of major disinterest and skepticism from 
the commercial side, usually due to misunderstanding of the marketing potential or medical need. Other examples include the discoveries by Nobel laureate James Black of the first beta-blocker, propranolol (Inderal), and the first $\mathrm{H} 2$ antagonist, cimetidine (Tagamet). "Who needs this $\mathrm{H} 2$ thing when we have such great antacids?” was heard as a chorus. Squibb \& Co. almost did not market captopril (Capoten) (the first angiotensin-converting enzyme inhibitor), even when it was approved by the FDA, because of initially very restrictive labeling. Similar difficulties occurred at Merck with lovastatin (Mevacor), the first statin, as well as with many breakthroughs by David Jack, Paul Janssen, and Leo Stenback. The extraordinary success of none of these drugs was predicted before marketing. But these lessons are so easily forgotten! An indispensable success factor, which today has virtually disappeared, is the role of "champions." Every successful drug has had at least one individual who in some way became a strong proponent for its development. This person(s) fostered understanding, encouragement, enthusiasm, patience, commitment, and assured the necessary resources. Precipitous discontinuations were thus often avoided, and efforts to resolve problems were enhanced. Champions are now rare; people are discouraged by the risk of being "wrong" ( 9 , $10)$. The culture that discourages champions also rejects the expression of passion, confusing this with the loss of objectivity.

Predicting commercial success is difficult, so how to proceed? Clearly, it is exceedingly difficult to predict the technical or commercial outcomes of novel compounds. One needs to focus instead on the novelty and relevance of the science, the technical rationale, basic pathophysiology, predictability of animal models, availability of human disease models, feasibility of development, and the future potential medical need as perceived through knowledge, experience, and instinct of scientists and physician-scientists. One must proceed with conviction that some of the novel compounds in the portfolio, all of which should have sound inherent scientific merit, will overcome the obstacles in development and provide real value, despite perceptions of potentially limited sales. If a new drug turns out to be of great medical value but has limited sales, there is nevertheless real value to the corporation in terms of the pride experienced by the company and its employees, prestige and respect in the medical community, and recruitment of talented employees.

Orphan drugs and drug pricing. In the 1960s through 1990s orphan diseases were simply rare diseases for which drug companies did not wish to initiate discovery programs, for commercial reasons. It was understood that prices could not be adjusted out of line with the prevailing standards. Such pricing concerns applied especially to cancers, because of the appearance of a lack of compassion. Commercial people were uncomfortable because they felt that they would have to essentially "give them away." Still, when opportunities presented themselves, they were not discarded, and the companies became proud of these products, even if they were not commercially rewarding. Thus, in the 1960 s-1980s a significant number of effective drugs for leukemias and lymphomas (especially Hodgkins disease) were introduced.

In 1983, the U.S. Congress passed the Orphan Drug Act to provide tax, funding, and exclusivity incentives to companies developing drugs for low-prevalence diseases (defined as fewer than 200,000 cases) that were not expected to provide investment returns. Industry embraced and used the provisions of the act for years. However, this situation has changed drastically in recent years, especially regarding lethal cancers and other rare genetic diseases. Good drugs have been introduced recently for some of these disorders, but the pricing practices could be considered scandalous (11). Prices do not relate to the costs of R\&D for these drugs, or to the costs of goods. Some companies now apparently feel that desperate patients (and society) will pay whatever is charged. Some examples (11) include Rituxan (for lymphoma; which costs about $\$ 13,000-\$ 25,000$ per cycle), Herceptin (breast cancer; about $\$ 3,200$ per month), Avastin (colorectal cancer; about $\$ 14,400$ per month), Revlimid (multiple myeloma; about $\$ 60,000$ per year), Erbitux (head and neck cancer; about $\$ 110,000$ a year), and Cerezyme (Gaucher disease; between $\$ 200,000$ [children] and $\$ 600,000$ [adults] per year). The ability to commercially exploit small sectors in the cancer field (e.g., 5,000 patients) by pricing and high profits has stimulated spectacular success in discovery research and rapid development (12), demonstrating, cynically, the current technical capacity of major companies to apply modern science to many diseases.

\section{Nearly all drugs that have become blockbusters had early histories of major disinterest and skepticism.}

Reasons for loss of compounds during development are changing. As mentioned earlier, the majority $(80 \%-90 \%)$ of compounds entering clinical testing do not make it to the market. This very high attrition rate is nearly always blamed on technical problems. In my experience, however, in at least a fourth of cases today, drugs are discarded during development for reasons that are not technical or scientific in nature.

The major nontechnical reasons for discontinuations are the result of marketing reassessments or management discontent. Most occur before sufficient data are available to make informed judgments. Often, a project simply becomes low priority. Since "resources are scarce," something has to go. Formal prioritization is today a management obsession, intended to remove appearances of doubt in decision-making. Priority lists are sacrosanct, infrequently revised, and followed religiously. It is not important whether or not two or more compounds are competing for the same resource in a rate-limiting way. This can lead to bad decisions. It is easier to check lists and make decisions with minimal thinking, agonizing, weighing things, and making judgments on an ongoing basis.

New management often has different interests and perceptions, or people just get tired or discouraged and nobody is beating the drums for the project. A 10 -year development period is an exceedingly long time for sustaining enthusiasm, focus, and nurturing and maintaining continuity of leadership/management. Such factors, although understandable, are subjective and arbitrary and not scientifically based. The same reasons that lead to project discontinuations also discourage the resolve to work out a new technical problem, which then serves as a convenient excuse for cutting a project for which management has lost interest. Amazingly, Pharmas will seldom out-license rejected compounds, even with generous buy-back provisions. The major reasons are fear of embarrassment (i.e., the appearance of having "bad judgment") should the compound become a success and the fear that important trade secrets may be passed on inadvertently.

Since the overall rate of attrition today is similar to that of previous decades, when loss of projects for nontechnical reasons was rare, it follows that the ability to predict technical success in development is actually better that in earlier eras - contrary to prevailing views. 
Planning departments are now in control of most of the development process, based on the belief that good planning assures accomplishment. Planners are enamored with theoretical and cookie-cutter program evaluation and review technique (PERT) charts, milestones, and "decision trees." In this atmosphere it is difficult to proceed thoughtfully based on the growing body of data - to "go with the science" (10). Decision-making is managed simplistically by following preestablished, expected outcomes at so-called "go-no-go" decision points. It is black and white; the mentality is that there is no need to agonize over decisions. Avoiding the thinking process does not serve research well. Similarly, nontechnical management often concludes that research people always have "too many projects" and that they are unable to discontinue their pet projects, so it is done for them. Managers thus can make illogical discontinuations to please their bosses. How many scientists enjoy working on a poor idea or an unsuccessful program?

Every single drug discussed above (AZT, acyclovir, bupropion, gabapentin, troglitazone, fluoxetine, captopril, cimetidine, propranolol, lovastatin, etc.), as well as virtually all other breakthrough drugs ever marketed, encountered serious technical problems that jeopardized development. Most problems were so severe that the compounds would have been discarded under our current wellmanaged and efficient go-no-go systems. The problems faced by each of these drugs were different and difficult to solve.

Separation of research from development. The process of drug D\&D is a continuum without clear, categorical separations. Today this is not understood, as illustrated by the fact that most Pharmas have separated their D\&D divisions organizationally, operationally, and often geographically. This reduces communication, cross-fertilization, cooperation, and teamwork. It diminishes the potential for basic researchers to solve problems arising during development. The "hands-off" mentality (i.e., give us the compound, we'll take it from here) results from the unrealistic presumption that development can be predictably managed.

Disinterest in new technologies. There are exciting opportunities for advancing the therapeutic value of drugs through pharmacogenomics (identifying subpopulations of patients based on response, side effects, or metabolism). Genetic techniques can uncover the molecular basis of subclasses of diseases or diseases of unknown etiology, which could provide new therapeutic targets. But these opportunities are often ignored by the industry, which focuses rather on "one pill for all," despite the fact that only a certain proportion of patients may benefit. Why develop and market a drug that treats only $10 \%-20 \%$ of patients, with a requirement to identify these before treatment starts?

Even in clinical trial design, there has been little exploration of new paradigms based on modern science. Current practices have changed little in 3 decades. Statistical theory and regulations drive trial design, under the fundamentally faulty assumption that human populations are homogeneous. As a result, an unnecessary number of very large, costly, and low-sensitivity trials are conducted or required by the FDA.

\section{The future of pharma: a change in focus?}

Perhaps Pharmas should shift their R\&D focus away from novel discovery and toward development areas in which they excel. These include improved formulations, compounds with superior pharmacokinetics, and analogs of known drugs with significant benefits. Incremental improvements have historically been among the most important approaches to advances in therapeutic agents.
Enhancing potency; reducing or eliminating a side effect; limiting dosage to once-daily (leading to improved compliance); enhancing bioavailability (resulting in less variation in the blood level of a drug); decreasing pill size (making them easier to swallow, increasing compliance); and overcoming drug resistance (in the case of antibiotics, antivirals, anticancer drugs) are changes that can result in valuable therapeutic contributions (not simply "metoo" drugs). These may not be as lucrative as new and possibly blockbuster drugs, but the costs and risks in their D\&D will be drastically decreased. Also, these kinds of products are more rational than some recent ones that are counterscientific and designed to achieve big sales rather than meet medical needs. Examples are fixed-dose combinations of drugs to treat 2 or more unrelated conditions simply because they happen to coexist in many individuals (e.g., hypertension, dyslipidemias, arthritis, diabetes, etc.). Genomic sciences increasingly point to the logic of doing just the opposite, the individualization of therapeutics.

Can small biotech companies contribute more? Because of their small size, such companies may offer attractive alternatives. However, these companies have funding constraints that dictate a narrow technical focus. The overriding objectives of those controlling the purse strings (venture capitalists) are short-term and financial. In most, sooner or later, unreasonable and disruptive demands are made on scientific operations. Venture capitalists are often disinterested in vanguard science and want only advanced compounds that appear "safe." Collaborations with major funding from pharma have lost appeal. Deals are often terminated suddenly, capriciously, or because pharma no longer perceives the potential for a blockbuster. Termination stalls the program and may cause it to languish or die. This industry has a role, but it is not one of replacing the primary existing systems. A few of these companies do succeed, but rarely, and in totality, like pharma, this industry is not very productive.

\section{A larger role for nonprofit institutions?}

An attractive alternative to the current, nearly exclusive role played by industry is to enhance the drug R\&D efforts in nonprofit biomedical research institutions, mainly universities, private research institutes, and government laboratories. These institutions have the appropriate climate for creative and innovative science. They understand the value of individual freedom, intellectual diversity, flexibility, and originality. Their science is not dictated by marketing or commercial objectives. Scientific collaborations are based on equality and contribution, not authoritative commands. These are places where cutting-edge science is done, and they attract the sharpest minds and bright young people. They have expertise in many disciplines in the biological, medical, chemical, computational, engineering, and mathematical sciences. The notion that academics normally engage in basic research while industry focuses on "applied research" is a myth based on misunderstanding of the nature of scientific research (13). Further, nonprofit biomedical research today is big-time, totally modernized, and unlike the caricatures of a sleepy environment for detached academics and scholars. The private sector could readily further mobilize to enhance its efforts in drug discovery as well as development. The maturation of the contract research organization (CRO) industry has been extensive and provides a source for competencies for regulatory-driven activities in development that anyone can utilize, as demonstrated by the successes of some biotech companies.

There are many activities now unfolding that are boldly extending research to the area of drug D\&D. Some of the scientific ratio- 
nale for this has recently been discussed by Duyk (14). The field of translational medicine, which generally refers to efforts by nonindustry scientists to bring basic discoveries to the clinic, has been exploding (15). Universities and research institutes have created departments or units of drug discovery or of translational medicine. The NIH has vigorously undertaken important new efforts in drug discovery. Although individual institutes have had drug discovery programs for decades (e.g., in epilepsy, cancer, HIV), a new approach has been initiated that involves an amalgamated NIH (16). The multiyear program has already established a 10center network ( 1 intramural, 9 others outside of NIH) to screen potential drug targets. They have initiated dozens of other funding opportunities, such as soliciting studies of high-throughput screening of molecular libraries and establishing Exploratory Centers for Cheminformatics Research (17).

These efforts are important for encouraging nonprofit institutions to initiate or increase research in drug discovery. However, this does not mean that the perpetuation and expansion of such programs should remain under the direction of the NIH or in competition with the NIH for funding. Such a role could lamentably end up redirecting the primary focus of the NIH, squeezing its budgets away from funding fundamental research (18). Current NIH budgets are in serious crisis $(18,19)$, as are those of the FDA (5) and other scientific agencies.

1. Booth, B., and Zemmel, R. 2004. Prospects for productivity. Nat. Rev. Drug Discov. 3:451-456.

2. Frantz, S. 2004. FDA publishes analysis of the pipeline problem. Nat. Rev. Drug Discov. 3:279.

3. Mervis, J. 2005. Productivity counts - but the definition is key. Science. 309:726-727.

4. Wood, A.J.J. 2006. A proposal for radical changes in the drug-approval process. N. Engl. J. Med. 355:618-623.

5. Kennedy, D. 2006. FDA centennial [editorial]. Science. 312:19.

6. Miller, H.I. 2005. September 2. Improving the drug approval process [editorial]. The San Diego Union-Tribune.

7. Avorn, J. 2005. FDA standards - good enough for government work? N. Engl. J. Med. 353:969-972.

8. Okie, S. 2005. What ails the FDA? N. Engl. J. Med.

\section{Market forces would dictate future changes in industry}

Major success in discovery research in the nonprofit sector would likely encourage corporate management and shareholders to abandon discovery research for economic reasons. How much and what kind of development drug companies would perform would depend on how they fare with the competition, particularly with regard to public institutions working in concert with CROs. However, one would expect that Pharmas' unique strengths would lead them to focus on efforts to develop new formulations and dosage forms of existing drugs, improvements in the methods to scale-up organic synthesis, and analogs with improved properties, as well as manufacturing, distribution, marketing, and selling of virtually all products.

\section{Acknowledgments}

The author is grateful to Alan R. Saltiel, Stephen Weiss, Robert E. Davis, Wendell Wierenga, Jerrold M. Olefsky, Joe Graedon, and Teresa Graedon for their critical review of the manuscript and for excellent suggestions.

Address correspondence to: Pedro Cuatrecasas, Departments of Pharmacology and Medicine, University of California, PO Box 2249, Rancho Santa Fe, California 92067, USA. Phone: (858) 7560908; Fax: (858) 759-8011; E-mail: pedrocuatrecasas@znet.com.
352:1063-1066.

9. Cuatrecasas, P. 1995. Corporate America: creativity held hostage. In Creative action in organizations. C.M. Ford and D.A. Gioia, editors. Sage Publications. Thousand Oaks, California, USA. 201-205.

10. Cuatrecasas, P. 1991. Devising the portfolio. In Creating the right environment for drug discovery. S.R. Walker, editor. Quay Publishing. London, United Kingdom. 51-65.

11. Graedon, J., and Graedon, T. 2005. Orphan drugs have become big business. The People's Pharmacy. http://www.peoplespharmacy.org/archives/editorial/orphan_drugs_have_become_big_business.asp.

12. Druker, B.J. 2006. Circumventing resistance to kinase-inhibitor therapy. N. Engl. J. Med. 354:2594-2596.

13. Cuatrecasas, P. 1992. Industry-university alli- ances in biomedical research. J. Clin. Pharmacol. 32:100-106.

14. Duyk, G. 2003. Attrition and translation. Science. 302:603-605.

15. Kaiser, J. 2006. A cure for medicine's ailments? Science. 311:1852-1854.

16. Couzin, J. 2003. NIH dives into drug discovery. Science. 302:218-222.

17. Office of Portfolio Analysis and Strategic Initiatives. 2006. Molecular libraries and imaging: NIH Roadmap for medical research. http://nihroadmap. nih.gov/molecularlibraries/fundedresearch.asp.

18. Marks, R.M. 2006. Rescuing the NIH before it is too late [editorial]. J. Clin. Invest. 116:844. doi:10.1172/ JCI28364.

19. Loscalzo, J. 2006. The NIH budget and the future of biomedical research. N. Engl. J. Med. 354:1665-1667. 